\title{
Signals in equity-based crowdfunding and risk of failure
}

\author{
Felix Reichenbach and Martin Walther ${ }^{*}$ (])
}

\author{
${ }^{*}$ Correspondence: \\ martin.walther@tu-berlin.de \\ Chair of Finance \\ and Investment, Technische \\ Universität Berlin, Sec. H \\ 64, Straße des 17. Juni 135, \\ 10623 Berlin, Germany
}

\begin{abstract}
This study investigates signal validity in equity-based crowdfunding by examining whether signals that increase crowd participation are associated with higher postoffering success. Post-offering success is measured as the probability of survival. We use a hand-collected data set of 88 campaigns with over 64,000 investments and 742 updates from a well-established and leading German equity-based crowdfunding platform, Companisto. We find that indicating that the chief executive officer holds a university degree and a higher number of business-related updates are associated with a lower risk of failure, which is in line with recent research on offering success. The number of updates on external certification, promotions, and the team is associated with a higher risk of failure. In contrast to recent findings on offering success, we find that the equity share offered is positively related to post-offering success, whereas a high number of large investments or updates on campaign development are accompanied by a higher probability of failure. Our results provide guidance for entrepreneurs and investors regarding which signals are worth sending or using. Furthermore, these results suggest that investors are partly using wrong signals and challenge the rationality and wisdom of the crowd.
\end{abstract}

Keywords: Equity-based crowdfunding, Post-offering success, Startup failure, Signaling, Startups, Updates

JEL Classification: D80, G33, L26, M13

\section{Introduction}

In recent years, the importance of crowdfunding has increased significantly. In particular, the brokerage for equity-like forms of financing to startups via Internet-based crowdfunding platforms has showed strong growth (Pichler and Tezza 2016). Consequently, the interest in the research on this topic has grown (Block et al. 2018b, 2020). Extensive research has thus been conducted on the signals provided during crowdfunding campaigns that influence investors' investment behavior (Vismara 2018b).

However, since Internet-based crowdfunding is a relatively new phenomenon, only a few studies have been conducted on venture performance after the completion of the crowdfunding campaign (Cumming et al. 2019; Hornuf et al. 2018; Signori and Vismara 2016, 2018). Such studies are important because they can clarify whether the signals used by investors actually offer valuable information on the future success of the

(c) The Author(s), 2021. Open Access This article is licensed under a Creative Commons Attribution 4.0 International License, which permits use, sharing, adaptation, distribution and reproduction in any medium or format, as long as you give appropriate credit to the original author(s) and the source, provide a link to the Creative Commons licence, and indicate if changes were made. The images or other third party material in this article are included in the article's Creative Commons licence, unless indicated otherwise in a credit line to the material. If material is not included in the article's Creative Commons licence and your intended use is not permitted by statutory regulation or exceeds the permitted use, you will need to obtain permission directly from the copyright holder. To view a copy of this licence, visit http:// creativecommons.org/licenses/by/4.0/. 
financed ventures. Our study attempts to address this research gap on signal validity by examining whether the signals provided during the crowdfunding campaign, which have an impact on offering success, also correlate with the subsequent failure risk. It differs from other studies that have investigated factors influencing the post-offering performance of startups by explicitly focusing on previously identified signals in the equitybased crowdfunding literature on offering success. In other words, our study examines whether the signals used by crowd investors actually increase their financial success. Thus, our study also examines the rationality and wisdom of the crowd.

We use a hand-collected data set from Companisto, one of the leading German crowdfunding platforms with a market share of more than 20\% in 2018 (Crowdfunding.de 2018). Our data set contains data about over 64,000 investments and 742 updates. We collect data on potential venture insolvencies until October 2020. During the period considered, Companisto offered lending-based and equity-based crowdfunding. We only examine the latter, which accounted for the largest share by far. In 2019, Companisto transformed from a crowdfunding platform for small investors to a platform focusing on more sophisticated investors. Initially, the platform was characterized by small minimum investments, public campaigns, and equity-like participatory loans. However, since the end of 2019, only accredited investors are provided access to the campaigns offering equity shares.

Using logit and Cox regression models and in line with the literature on signals, we demonstrate that a venture's risk of failure decreases if its chief executive officer (CEO) states that they hold a university degree. A higher number of business-related updates is associated with a lower risk of failure. The number of updates on external certification, promotions, and the team is associated with a higher risk of failure. However, contradicting the findings of recent research on offering success, we find that large investments during the crowdfunding campaign and the number of updates on campaign development are associated with a higher probability of failure. Furthermore, we show that the risk of failure decreases with the equity stake offered.

Our findings have implications for entrepreneurs, investors, and platform design. For example, entrepreneurs can send credible signals by indicating their university degree or industry experience in the campaign description and by choosing a legal form with high personal liability for their venture. Crowd investors who are interested in maximizing their financial gains and minimizing the risk of failure should not consider small equity stakes and large investments of other investors as positive signals. They should also avoid investing in ventures that have already conducted another crowdfunding campaign. Regarding platform design, our result on large investments suggests that platforms could reduce misinterpretations about large investments by providing information on the investors' level of professionalism or investment experience, such as by giving them the option to mention their profession. Furthermore, our study emphasizes the importance of regulating investors' maximum investment amounts in equity crowdfunding, as has been recently introduced in the US (Securities and Exchange Commission 2015).

The remainder of our study is organized as follows: Section "Theory" presents the theory. In Section "Hypotheses development", we develop our hypotheses. Section "Data and variables" offers a description of the data set and variables. In Section "Methods", we explain the methods used. In Section "Results", we present the analysis results. In 
Section "Discussion", we discuss the implications and limitations of the study. Section "Summary" summarizes the paper.

\section{Theory}

Crowdfunding is a relatively new form of financing in which a project or a business receives financial resources from a large number of individual investors, mostly via the Internet (Belleflamme et al. 2014). Crowdfunding and other financial technologies make previously inaccessible investment opportunities available and affordable to almost everyone (Hasan et al. 2021). Thus, equity crowdfunding can contribute to the democratization of entrepreneurial finance by equity crowdfunding (Cumming et al. 2021). Typically, the first step in equity crowdfunding is that a startup applies to a platform. The startup is then presented on the platform's website for the duration of the campaign, and shares are offered. Investors can accept this offer and receive a stake in the venture in exchange for providing capital.

There are three relevant players in equity-based crowdfunding: the platform, the entrepreneurs or ventures, and a heterogeneous group of investors called the crowd. Depending on the platform, different services are offered to the ventures and investors before, during, and after the campaign. Rossi and Vismara (2018) show that post-campaign services in particular, such as exit assistance or a secondary market, can increase the attractiveness of platforms and lead to a higher number of successfully funded startups. Corporate governance mechanisms, such as the transfer of voting rights, the design of which is primarily driven by national regulation, can influence the platform's success as well (Rossi et al. 2019).

Startups applying for equity crowdfunding are often dependent on external backers to ensure their survival (Tech 2018). Crowdfunding represents an alternative to financing through business angels (BAs) in the early stages, when it may be difficult to obtain financing via banks or venture capitalists (VCs) (Leboeuf and Schwienbacher 2018). However, there are several other reasons for why ventures participate in crowdfunding, such as marketing effects and being able to contact potential customers and investors (Angerer et al. 2017).

The crowd is a group of heterogeneous investors who differ in terms of wealth and professionalism (Heminway 2013). While one of the main goals of investors is financial success, other objectives, such as supporting entrepreneurs or building networks, can play a role as well (Cholakova and Clarysse 2015). In this context, the question of whether the crowd acts rationally and can achieve better results as a group by interacting with other investors arises. This concept is called the wisdom of the crowd (Surowiecki 2004). Ahlers et al. (2015) show that investors pay extensive attention to the information provided on crowdfunding platforms and are influenced by it when making investment decisions. Furthermore, Vismara (2018a) finds that investors are prone to herding behavior, which refers to imitating other investors.

The relationship between investors and ventures, which is characterized by information asymmetries and high uncertainty about the risk of failure, can be considered a principal-agent relationship. The two most important problems occurring in this context are adverse selection (Akerlof 1970) and moral hazard (Arrow 1984). To reduce information asymmetry, and consequently, agency problems, screening (Stiglitz 1975) and 
signaling (Spence 1973) can be used. The former is mainly carried out before the campaign by platforms, which are interested in building a reputation as reliable intermediaries (Lambert et al. 2018). The latter can be performed by the ventures, which send signals providing investors with information on unobservable characteristics to present themselves as quality ventures and to achieve higher valuations. However, as shown in the next section, such information should only be used as quality signals if the senders subsequently experience above-average post-offering performance.

Specifically, on Companisto, potential investors are provided with the following information during the campaign: on the overview page, there is a video in which the founding team introduces itself and the business idea. Further information on the business model, the intended use of the funds, and often, information on reputable investors who already support the startup are also provided below the video. Short biographies list the qualifications of the team members. Important information that becomes known as the campaign progresses, such as the achievement of a milestone, is published in the form of updates. The behavior of other investors can be observed from their previous investments and comments.

\section{Hypotheses development}

In this section, we develop the hypotheses that we test in our study. First, we argue why the failure ratio is an important measure of venture success and why avoiding investing in failing startups is decisive for investors' returns. We then present the main idea behind the hypotheses and develop them by drawing from recent literature.

Startups are associated with a high risk of failure. Hall and Woodward (2010) show that nearly $75 \%$ of entrepreneurs who are backed by venture capital achieve an exit value of zero for their startup. According to organizational ecology literature (e.g. Wholey and Brittain 1986), this high failure ratio, which leads to strong skewness in the return distribution, can be attributed primarily to the small size of the startups, which puts them at a disadvantage when competing with established companies (liability of smallness) and to their short previous existence (liability of newness). Apart from high risk, investments in startups acquired through crowdfunding are illiquid. Therefore, investors should demand high risk premiums in the form of high expected returns (Amihud 2002; Markowitz 1952). However, the results of recent studies and publications by the platforms themselves (e.g. AltFi 2015; Hornuf and Schmitt 2016; Seedmatch 2018; Signori and Vismara 2016) on possible returns in equity-based crowdfunding are ambiguous. This can partly be attributed to different calculation methods (actual returns versus returns based on valuations) and to the lack of sufficient data, particularly on the rare event of exits. The studies, however, reveal that the probability of failure plays a decisive role in returns. Investors should, therefore, have a strong interest in avoiding failures. Additionally, using data from the peer-to-peer lending platform Lending Club, Wang et al. (2021) show that reducing the costs linked to failures is essential for the survival and profitability of financing platforms. Therefore, our results are likely to be of interest to crowdfunding platforms.

Our hypotheses are based on the following idea: if the crowd pursues financial goals and is rational, it should invest more in campaigns that perform well after the completion of the campaign. Hence, signals that have an impact on the crowd's investment 
behavior should be related to post-offering success in the same direction. Otherwise, they should not be considered quality signals. In the following sub-sections, we present this concept in more detail by examining the relationship between the campaign and post-offering success to derive five hypotheses.

\section{Offering and post-offering success}

Recent research has shown the effects of certain types of information on campaign success. Some examples are updates during the campaign (Hornuf and Schwienbacher 2018), information on entrepreneurs (Ahlers et al. 2015; Piva and Rossi-Lamastra 2018), indication of the support of professional investors (Ralcheva and Roosenboom 2016), and the equity stake offered (Ahlers et al. 2015). Furthermore, other investors' behavior can also be considered a signal. In this context, Hornuf and Schwienbacher (2018) demonstrate that large investment amounts and positive comments lead to a larger number of investments in the days following such investments and comments. Similarly, Walther and Bade (2020) show that large investments in the campaign increase investors' willingness to pay.

However, investors' belief in the effectiveness of such information as indicators of future success is not sufficient for it to actually be considered a quality signal. Rather, these must be continuously confirmed by subsequent positive experiences, meaning that the ventures that generated the signal should demonstrate an above-average development, so that a separation equilibrium can be achieved (Spence 2002). Consequently, "studies on signal certification and post-signal performance $[. .$.$] are central in identify-$ ing effective signals," and it "is particularly important for the future of these markets to demonstrate signals' validity" (Vismara 2018b, p. 30). Thus, the underlying idea of our study is as follows: if the crowd behaves rationally and investors try to maximize their financial success, they should only use signals that lead to better investments in terms of post-offering success. Therefore, signals that influence offering success should be related to post-offering success in the same direction. Otherwise, using such signals would lead to a higher risk of failure, and consequently, worse investments. In such a case, the signals should not be considered quality signals, and investors should accordingly modify their behavior. Thus, in a sense, our study examines the extent to which the crowd acts rationally and whether the wisdom of the crowd helps it to distinguish promising from less-promising startups.

Before formulating the hypotheses, it is necessary to summarize the results of recent research on post-offering success, as we will draw on these findings for the control variables. Using data from Germany and the United Kingdom (UK), Hornuf et al. (2018) find that the number of senior managers is negatively related to the probability of failure. A higher valuation of the venture and a higher number of initial VC investors are associated with a higher risk of failure. Their results further indicate that the venture's legal form and whether the venture is located in a big city may have an impact on the probability of failure.

Signori and Vismara $(2016,2018)$ investigate the post-offering outcomes of 212 campaigns from Crowdcube. Their study findings reveal that older ventures and ventures that already reported positive sales before the crowdfunding campaign are less likely 
to fail. Furthermore, tax incentives and voting rights have a significant effect on postoffering success.

Cumming et al. (2019) examine 491 campaigns on Crowdcube. They find similar effects for positive sales and venture age. Moreover, in their sample, family businesses are less likely to fail. In contrast, a higher separation between ownership and control rights increases the risk of failure.

\section{Hypotheses}

Despite the large number of potential signals (for example, as listed by Block et al. 2018a; Vismara 2018b), our study focuses on selected potential signals that fulfill two criteria. First, the information used as a signal must be accessible and visible to any investor on the studied platform because it cannot be considered otherwise. Second, recent research must have found a relation between the signal and investor behavior in equity-based crowdfunding. In the following paragraphs, we address each signal separately and explain why its investigation is particularly relevant. The literature on the effects of these signals on offering and post-offering success is summarized in Table 1, which we refer to when developing the hypotheses.

For all the signals, we proceed as follows: first, we present the theory and existing literature on campaign success and, subsequently, on post-offering success. Then we formulate the hypothesis based on the previously explained concept that information that has been shown to increase campaign success can only be a quality signal if it also has an analogous effect on post-offering success (measured in terms of the startup's probability of survival).

\section{University degree}

The human capital of a startup is an important decision criterion for VCs and other professional investors (Ng et al. 2017). In equity-based crowdfunding, signals pertaining to human capital are likely to be even more important, as risk and information asymmetries are particularly large. By being exposed to theoretical concepts and analytical thinking as part of their education, entrepreneurs can better identify business opportunities and analyze costs, organizational structures, customer needs, and the competitive environment (Piva and Rossi-Lamastra 2018). The positive effect of indicating a university degree (in economics) on the number of investors and campaign success has been shown in the case of the Australian platform ASSOB and the Italian platform SiamoSoci (Ahlers et al. 2015; Piva and Rossi-Lamastra 2018). In addition, using data from Companisto, Goethner et al. (2020) demonstrate that a PhD of at least one member of the team increases the probability of investments.

However, we are the not aware of research that investigates how the CEO's university degree is related to post-offering success in equity crowdfunding, which is necessary to validate the signal. Therefore, we formulate Hypothesis 1 (H1) as follows:

Startups with CEOs who state that they have a university degree have a lower probability of failure. 
Table 1 Summary of the literature on offering and post-offering success

\begin{tabular}{ll}
\hline Signal & Studies on offering success \\
\hline University degree & $\begin{array}{c}\text { A degree (in economics) increases the num- } \\
\text { ber of investors on: } \\
\text { - }\end{array}$ \\
& - SSSOB (Ahlers et al. 2015) \\
In addition, Goethner et al. (2020) demon- & strate on Companisto that a PhD increases \\
& the probability of investments. \\
Aquity stake offered & A decrease of the equity offered is associ- \\
& ated with a higher number of investors on: \\
& - ASSOB (Ahlers et al. 2015) \\
& - Crowdcube (Ralcheva and Roosenboom \\
& 2016) \\
- Crowdcube and Seedrs (Vismara 2016) & Smaller equity stakes offered increase the \\
& chances to reach the funding target on \\
& Crowdcube (Cumming et al. 2019).
\end{tabular}

Reputable (professional) investors

Large investments

Updates
Support by reputable (professional) investors is positively related to the number of investors on Crowdcube (Ralcheva and Roosenboom 2016).

Large investments of other investors have a positive effect on willingness to invest:

- Hornuf and Schwienbacher (2018) demonstrate a positive effect of large investment on the number of investments in the subsequent days on Companisto and three other German platforms

- Walther and Bade (2020) show that large investments increase investors' willingness to pay on Companisto

An update increases the number of investments on various German platforms including Companisto (Bade and Walther 2021; Block et al. 2018a; Hornuf and Schwienbacher 2018). Block et al. (2018a) also show that the investor reaction depends on the updates' content.
Studies on post-offering success

To the best of our knowledge, our study is the first to investigate the relationship between a university degree of the CEO and post-offering success.

Recent studies provide mixed results. The following results indicate that smaller equity stakes offered are positively related to post-offering success in the UK:

- Cumming et al. (2019) find that smaller levels of equity offered increase the likelihood of success and decrease the probability of failure (Crowdcube, UK)

- Signori and Vismara (2018) find no significant effect on the risk of failure (Crowdcube, UK)

- Signori and Vismara (2016) find that equity offered is negatively related to the probability of seasoned equity offerings, which they consider a success (Crowdcube, UK)

In contrast, Hornuf et al. (2018) find that higher equity stakes offered are associated with lower probabilities of failure using a sample of 13 platforms from the UK and Germany.

Our study attempts to clarify the role of equity offered on the German equitybased crowdfunding market. This is of particular interest as other forms of financial instruments (without voting rights) are used in Germany.

Mixed results on the effects of reputable (professional) investors exist.

Signori and Vismara (2018) find a positive effect of professional investor backing on post-offering success. In their sample no venture that was backed by professional investors failed subsequently.

In contrast, Hornuf et al. (2018) find that a higher number of initial VC investors is associated with a higher probability of failure.

With our study, we want to test how reputable investor backing and post-offering success are related in Germany.

To the best of our knowledge, our study is the first to study the relationship of large investments and post-offering outcomes.

To the best of our knowledge, our study is the first to investigate the relationship between the number of updates and post-offering outcomes. 


\section{Equity stake offered}

Several studies report a negative relationship between the equity stake offered and the number of investors in the crowdfunding campaign (Ahlers et al. 2015; Cumming et al. 2019; Ralcheva and Roosenboom 2016; Vismara 2016). The management's willingness to invest in its own company is an important signal of venture quality (Leland and Pyle 1977). As insiders, entrepreneurs have insights into their venture that external investors may not have. Consequently, if entrepreneurs are optimistic about the future development of their business, they would prefer to sell only a small share of their startup (Vismara 2016). Furthermore, if entrepreneurs hold large equity shares, disincentives, and consequently, moral hazard problems reduce.

Recent studies provide mixed results on the relationship between the equity stake offered and post-offering success. Signori and Vismara (2018) find no significant effect of the equity stake on the probability of firm failure. Signori and Vismara (2016) find that the equity offered is negatively related to the probability of seasoned equity offerings, which they consider a success (Crowdcube, UK). In Cumming et al. (2019), smaller levels of equity offered are associated with an increase in the likelihood of success and a decrease in the probability of failure. Overall, equity retention by entrepreneurs seems to increase post-offering success in the UK. However, in contrast to these studies, Hornuf et al. (2018) report that the percentage of shares offered reduces the risk of failure in their sample. Interestingly, almost two-thirds of their data set are also British campaigns. Our study attempts to clarify the role of equity offered on the German equitybased crowdfunding market. This is of particular interest, as other forms of financial instruments (such as participatory loans without voting rights) were used in Germany. We therefore formulate the following hypothesis:

Hypothesis 2 (H2): Startups that offer low equity stakes have a lower probability of failure.

\section{Reputable investor backing}

Owing to personal contact with entrepreneurs, investment expertise, and the ability to bear higher screening costs, professional investors may have superior information compared to other investors. In addition, professional investors might risk their reputation by visibly supporting a campaign if the startup subsequently fails. Thus, the prior investments of professionals can be seen as a positive signal (Ralcheva and Roosenboom 2016). In addition, professional investors provide other advantages such as access to networks, consulting, and the possibility of increasing their investment in the future (Stubner et al. 2007). Using data from Crowdcube, Ralcheva and Roosenboom (2016) show that small investors prefer startups that are supported by professional investors.

Regarding post-offering success, Signori and Vismara (2018) find a positive effect of professional investor backing. In their sample, no venture backed by professional investors failed eventually. In contrast, Hornuf et al. (2018) find that a higher number of initial VC investors is associated with a higher probability of failure. Given these mixed results, our study can provide more clarity on the role of support from reputable investors. We therefore formulate the following hypothesis: 
Hypothesis 3 (H3): Startups that indicate support by reputable investors have a lower probability of failure.

\section{Large investments}

Large investments by other investors during the crowdfunding campaign could also be interpreted as a signal. These investors are likely to be financially sound, making it more viable for them to screen and take on the high fixed costs. Investors with small wealth may thus assume that these investors have superior information. Therefore, imitating the actions of investors who invested large amounts might be rational. Hornuf and Schwienbacher (2018) and Walther and Bade (2020) identify herding behavior in the German equity-based crowdfunding market. In particular, the former find that investments of $€ 5,000$ or $€ 10,000$ increase the number of investments on the following days, while the latter demonstrate that large campaign investments result in a higher willingness to pay. In this study, we define large investments as investments that amount to at least $€ 5,000$. Thus, our results are comparable to the results on offering success by Hornuf and Schwienbacher (2018), who also use data from Companisto.

If large investments are indeed positive signals, they must be positively related to the probability of survival. To the extent of our knowledge, no other studies have been conducted on this topic. We therefore formulate the following hypothesis:

Hypothesis $4(\mathrm{H} 4)$ : Large investments during the crowdfunding campaign are associated with a lower probability of failure.

\section{Updates}

Updates enable startups to communicate information on new collaborations, external investors, or business developments that was not known at the start of the campaign (Block et al. 2018a). Updates thus reduce the screening costs of potential investors. Furthermore, updates can be used strategically to regain attention to the campaign (Angerer et al. 2017; Dorfleitner et al. 2018). Block et al. (2018a), Bade and Walther (2021) and Hornuf and Schwienbacher (2018) find a positive relation between updates and the success of the crowdfunding campaign. However, Block et al. (2018a) also show that the investor reaction depends on the content of the updates and that some types of updates, such as those on external certification, are even followed by fewer investments.

To the best of our knowledge, we are the first to investigate how the number of updates and their content are related to post-offering success. To be a quality signal, the number of updates should be associated with a lower risk of failure. We therefore formulate the following hypothesis:

Hypothesis $\mathbf{5}$ (H5): A higher number of updates is associated with a lower risk of failure.

Additionally, we examine whether different types of updates have different effects on the probability of failure. 


\section{Data and variables}

In this section, we introduce our data set and variables and present descriptive statistics. The information on signals and the characteristics of the startups used in our model have been taken from the respective campaign page on Companisto's website. We used the website of the "Bundesanzeiger"1 as a source to obtain the legal form, the date of foundation and, where available, the date of the startup's failure.

As the first step, all campaigns that are listed on the platform and ended before May 1, 2019 (before Companisto changed its focus to more sophisticated investors) were included. Of these 105 campaigns, we excluded two real-estate projects and one film project. Six campaigns were lending-based, while the other 96 used equity-based crowdfunding. To ensure comparability, we included only equity-based crowdfunding campaigns in our analysis. Of these 96 campaigns, seven failed to reach the necessary funding threshold, resulting in the termination of the campaign. We included only the 89 successfully funded campaigns in the regression models discussed in the following sections. Furthermore, one campaign was removed due to missing values. On average, the considered startups were 2.98 years old with a standard deviation (SD) of 3.42 when the campaign ended and had collected $€ 550,000$ (SD: €770,000) from 729 investors (SD: 393).

In the second step, we manually collected information that can be used by investors as signals for each startup from its respective campaign website. Table 2 contains the variable definitions. Table 3 presents descriptive statistics and a t-test comparison between startups that failed and those that did not fail until the end of the observation period. ${ }^{2}$

In particular, we consider whether the $\mathrm{CEO}$ has stated that they hold a university degree (Degree), the equity stake offered (Equity offered), whether the startup has indicated that it is backed by investors who it classified as professional in the campaign description (Reputable investor backing), the number of investments over $€ 5,000$ (\#Invest $5 k$ ), and the number of updates (\#Updates).

To further break down the results and perform robustness checks, we include additional variables. Reputable investor backing is subdivided into backing by BAs (BA backing), VCs (VC backing), and other investors such as development banks ("Förderbanken") or well-established companies (Other investor backing). We also collect the number of

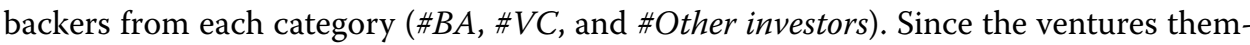
selves decide whether supporters are classified as professional, we refer to the reputable investors listed by the startups for indicating endorsement as professional investors in the campaign description. In addition, the number of actual investments made by corporations (as opposed to private investors) over the course of the campaign is used as a proxy for the professional support provided over the funding period (\#Corporate investments). We determine whether an investment is made by a corporation based on the

\footnotetext{
${ }^{1}$ The "Bundesanzeiger" is an official journal in which companies must disclose relevant information on, for example, foundation dates and changes in the legal form ("http://www.bundesanzeiger.de" and "http://www.unternehmensregister. de"). In addition, we used the business research site "http://www.northdata.de" and a data set provided by Crowdinvest for control purposes and compared the insolvency information with Companisto's data on failed startups on the campaign sites. See(BMJV (2020a, 2020b), Companisto (2020), Crowdinvest (2020), and North Data (2020).

${ }^{2}$ Note that we exclude all campaigns that failed to pass the financing threshold throughout the analysis. However, including failed campaigns and an additional dummy as control yields qualitatively similar results in all models.
} 
Table 2 Definitions of variables

\section{Dependent variable}

Failure

\section{Explanatory variables}

H1 Degree

$\mathrm{H} 2$ Equityoffered

H3 Reputable investor backing

BA backing

vc backing

Other investor backing

$\# B A$

\#VC

\#Other investors

\#Corporate Investments

H4 \#Invest5k

\#Invest5k corporate

\#Invest5k private

H5 \#Updates

\#Updates business development

\#Updates business model

\#Updates campaign development

\#Updates cooperation projects

\#Updates external certification

\#Updates new funding

\#Updates product development

\#Updates promotions

\#Updates team

\#Updates other

\section{Control variables}

Start campaign

Venture age

positive sales

\#Investors

Funding amount

Target attainment

Big city

Business value

Industry experience

Management size

Entrepreneurial company

Follow-up campaign
$1=$ startup failed during the observation period

$1=$ CEO states to hold a university degree

Equity offered in the campaign [in percentage points]

$1=$ startup states to be backed by reputable investors

$1=$ startup states to be backed by business angels

$1=$ startup states to be backed by venture capitalists

$1=$ startup states to be backed by other investors

Number of business angels listed as supporters

Number of venture capitalists listed as supporters

Number of other investors listed as supporters

Number of investments made by corporations during the campaign

Number of investments $\geq € 5,000$

Number of investments by corporations $\geq € 5,000$

Number of investments by private individuals $\geq € 5,000$

Number of updates during the campaign

Based on Block et al. (2018a): Thereof the number of updates that contain information on ...

... financial development of the startup and its customer base

... the business model, the relevant market, or future business orientation

... campaign updates or announcements that the funding limit has been changed

... about new collaborations the start-up engaged in

... expert opinions, success stories, news about awards received, patent applications, patent approvals as well as press and media coverages

... additional funding from business angels, venture capitalists or government grants

... the product, target costumers, prototypes, or new product inventions

... promotions the crowd may receive, open calls to participate via social media, invitations for personal meetings and appeals to investors to support the startup

... the entrepreneurial team (education, previous work experience)

Number of updates that do not fit in one of the previous categories

Start of the campaign, measured in years since the launch of Companisto

Age of the startup at the end of the campaign [in years]

$1=$ the startup reported positive sales before campaign start

Number of investors

Amount of capital raised [in $€$ million]

Ratio of collected to demanded funding amount

$1=$ venture is located in a city with more than a million inhabitants

Pre-money valuation of the venture [in $€$ million]

$1=$ the CEO states to have work experience in the industry of the startup

Number of members in the entrepreneurial team

$1=$ legal form is UG (haftungsbeschränkt)

$1=$ the venture already ran a campaign on Companisto before

This table presents the definitions of variables. The categorization of updates is based on Block et al. (2018a) 
Table 3 Descriptive statistics

\begin{tabular}{|c|c|c|c|c|c|c|}
\hline & & Mean & SD & Minimum & Maximum & t-test \\
\hline & \multicolumn{6}{|l|}{ Dependent variable } \\
\hline & Failure & 0.43 & 0.5 & 0 & 1 & - \\
\hline & \multicolumn{6}{|l|}{ Explanatory variables } \\
\hline H1 & Degree & 0.8 & 0.41 & 0 & 1 & -0.06 \\
\hline H2 & Equity offered & 12.53 & 6.96 & 2 & 38 & -0.25 \\
\hline \multirow[t]{8}{*}{ H3 } & Reputable investor backing & 0.74 & 0.44 & 0 & 1 & -0.14 \\
\hline & BA backing & 0.64 & 0.48 & 0 & 1 & -0.05 \\
\hline & VCbacking & 0.17 & 0.38 & 0 & 1 & 0.07 \\
\hline & Other investor backing & 0.22 & 0.41 & 0 & 1 & -0.1 \\
\hline & $\# B A$ & 2.2 & 3.65 & 0 & 30 & 1.03 \\
\hline & $\# V C$ & 0.32 & 0.84 & 0 & 4 & 0.09 \\
\hline & \#Other investors & 0.28 & 0.59 & 0 & 2 & -0.04 \\
\hline & \#Corporate Investments & 8.95 & 5.58 & 0 & 26 & 1.84 \\
\hline \multirow[t]{3}{*}{ H4 } & \#lnvest5k & 20.85 & 27.62 & 0 & 143 & 2.25 \\
\hline & \#Invest5k corporate & 1.26 & 1.54 & 0 & 6 & 0.19 \\
\hline & \#Invest5k private & 19.63 & 26.83 & 0 & 137 & 2.01 \\
\hline \multirow[t]{24}{*}{ H5 } & \#Updates & 8.43 & 4.63 & 2 & 26 & -0.76 \\
\hline & \#Updates business development & 1.77 & 1.91 & 0 & 12 & $-1.04^{* * *}$ \\
\hline & \#Updates business model & 0.66 & 0.79 & 0 & 5 & -0.23 \\
\hline & \#Updates campaign development & 1.53 & 1.49 & 0 & 7 & $0.68^{* *}$ \\
\hline & \#Updates cooperation projects & 0.93 & 1.21 & 0 & 6 & 0.07 \\
\hline & \#Updates external certification & 0.5 & 0.96 & 0 & 4 & 0.23 \\
\hline & \#Updates new funding & 0.35 & 0.77 & 0 & 4 & -0.11 \\
\hline & \#Updates product development & 0.9 & 1.36 & 0 & 6 & -0.05 \\
\hline & \#Updates promotions & 0.9 & 1.39 & 0 & 9 & 0.09 \\
\hline & \#Updates team & 0.27 & 0.56 & 0 & 2 & 0.17 \\
\hline & \#Updates other & 0.61 & 1.15 & 0 & 7 & $-0.57^{* *}$ \\
\hline & \multicolumn{6}{|l|}{ Control variables } \\
\hline & Start campaign & 3.24 & 1.88 & 0 & 6.5 & $-1.2^{* * *}$ \\
\hline & Venture age & 2.98 & 3.43 & 0.07 & 17.3 & $-1.23^{*}$ \\
\hline & Positive sales & 0.84 & 0.37 & 0 & 1 & 0 \\
\hline & \#Investors & 727.8 & 393.2 & 204 & 2276 & 88.5 \\
\hline & Funding amount & 0.55 & 0.77 & 0.04 & 5 & -0.08 \\
\hline & Target attainment & 0.88 & 0.45 & 0.08 & 2.5 & -0.12 \\
\hline & Big city & 0.66 & 0.48 & 0 & 1 & 0.09 \\
\hline & Business value & 4.65 & 7.71 & 0.65 & 50 & -0.84 \\
\hline & Industry experience & 0.48 & 0.5 & 0 & 1 & $-0.19^{*}$ \\
\hline & Management size & 4.23 & 1.73 & 2 & 10 & -0.08 \\
\hline & Entrepreneurial company & 0.08 & 0.27 & 0 & 1 & 0.09 \\
\hline & Follow-up campaign & 0.08 & 0.27 & 0 & 1 & 0 \\
\hline
\end{tabular}

This table presents mean, standard deviation (SD), minimum and maximum of each of the variables in the sample. The column "t-test" contains the difference of means of startups that fails and startups that did not fail during the observation period. The stars indicate the significance of this difference according to Welch's t-test $\left({ }^{*} p<0.1 ;{ }^{* *} p<0.05 ;{ }^{* *} p<0.01\right)$. For \#Invest $5 k$ corporate and \#Invest5k corporate 87 observations were available. The number of observations of all other variables is 88 . The categorization of updates is taken from Block et al. (2018a) 


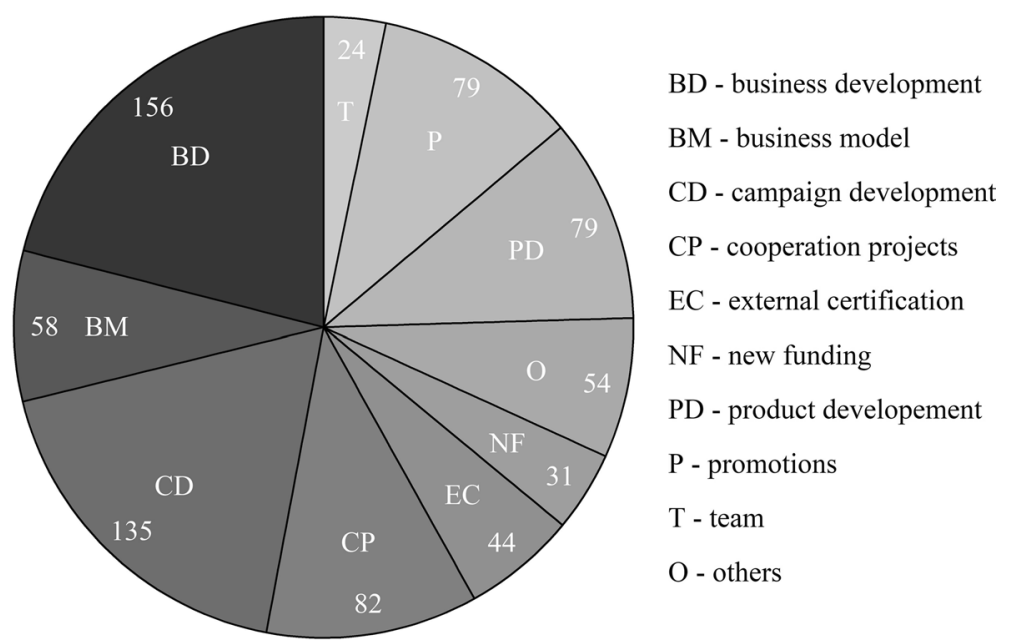

Fig. 1 Pie chart of update categories. This graphic depicts the distribution of updates across the categories as defined by Block et al. (2018a). The numbers represent the number of updates. The total number of updates is 742

names provided by the investors. ${ }^{3}$ Using this method, we include the number of corporate investments that exceeded $€ 5,000$ (\#Invest $5 k$ corporate) and the number of those made by private investors (\#Invest 5 k private). Finally, we differentiate the updates based on their content by grouping them into ten different categories, which we defined as indicated in Block et al. (2018a), to ensure comparability. Figure 1 shows the shares of each category of the total 742 updates during the 88 considered campaigns.

Additionally, we selected control variables based on the literature on post-offering presented in Section "Offering and post-offering success". The venture's pre-money valuation (Business value), the number of team members (Management size), and the age of the startup at the end of the campaign (Venture age) control for the liability of smallness and that of newness. We further consider whether the startup is located in a city with more than one million inhabitants (Big city), as access to investors and talented employees is likely to be much easier there. Moreover, we include the legal form. The founders of a so-called "UG" (Entrepreneurial company) are liable with a significantly lower amount compared to those of a "GmbH" (limited liability company) or "AG" (public limited company). We control for founder experience by including a dummy variable that equals 1 if the CEO has indicated work experience in the industry of the startup (Industry experience) ${ }^{5}$ Positive sales indicates the startup's economic performance and is assigned a value of 1 if the startup states that it has generated sales before the launch of the campaign. We also consider whether the startup had already run a campaign on Companisto, as this could indicate a lack of interest from other professional investors

\footnotetext{
${ }^{3}$ Specifically, we filtered the names by legal forms such as "GmbH", "GbR" or "AG", and other expressions that indicate that the investment was made by a corporation, such as "holding" or "venture".

${ }^{4}$ Note that most studies use different combinations of controls. For example, Hornuf et al. (2018) control for trademarks and patents and the average age of the senior management, while Cumming et al. (2019) include a dummy variable on whether the company owns or is filing patents. However, all of these yield insignificant coefficients, which is why we do not include them in our analysis.

${ }^{5}$ We also tested for the effects of the CEO's experience in founding or developing a startup and whether the CEO had already achieved a successful exit. However, these variables yield insignificant effects, which is why we do not report them.
} 
Table 4 Overview on failures and exits by year

\begin{tabular}{lllll}
\hline Year $(\mathbf{y})$ & $\begin{array}{l}\text { \# campaigns that start } \\
\text { in } \mathbf{y}\end{array}$ & \# failures in $\mathbf{y}$ & $\begin{array}{l}\text { \# active startups at the } \\
\text { end of } \mathbf{y}\end{array}$ & \# exits in $\mathbf{y}$ \\
\hline 2012 & 6 & 0 & 6 & 0 \\
2013 & 17 & 0 & 23 & 0 \\
2014 & 10 & 4 & 29 & 0 \\
2015 & 13 & 3 & 39 & 2 \\
2016 & 18 & 2 & 55 & 4 \\
2017 & 11 & 9 & 57 & 1 \\
2018 & 13 & 11 & 59 & 2 \\
2019 & 0 & 6 & 53 & 0 \\
2020 & 0 & 3 & 50 & 0 \\
\hline
\end{tabular}

(Follow-up campaign). In addition, a successful campaign might be seen as a positive signal in itself. Successful campaigns may help the startup attract the interest of professional investors and customers, which ultimately reduces the likelihood of failure. Therefore, the number of investors (\#Investors), the amount of financing received (Funding amount), and the ratio of collected to demanded funding amount (Target attainment) are considered as measures of the success of the campaign. Furthermore, we control for the timing of the campaign by including the variable Start campaign. This variable measures the time difference between the start of the campaign and the launch of Companisto in years. It controls for timing-related changes in the risk of failure. In addition, in the logit model, it controls for the fact that startups with crowdfunding campaigns that started later had less time to fail. The highly significant difference of -1.2 years in Start campaign between the startups that failed and those that did not (see t-test in Table 3) highlights the importance of including it in the logit regressions.

In addition, to control for company characteristics, we include industry dummies derived from Companisto's categorization of industries. Since these are very specific, we group them into the following categories: Apps and Software (30), Engineering (22), Lifestyle (24), Retail and E-Commerce (24), Transport and Tourism (10), and Other (7). The number of ventures in each category is stated in parentheses. Note that the same startup can be classified under several categories.

As a final step, we collected data on venture insolvencies until October 2020. Up to this point, 38 (43.2\%) financed startups had failed, while 9 (10.2\%) had exited. ${ }^{6}$ Table 4 indicates the annual numbers of these two events and the number of startups that are still active at the end of each year. It also shows the different start dates of the campaigns, which result in different observation periods. The implications for the statistical methods used are discussed in more detail in the next section. Furthermore, due to the low number of exits, the analysis in the next section is limited to startup failures.

To provide an initial overview on post-offering success, we estimate the probability of failure and exit over time by using the cumulative incidence function, which takes into account the different lengths of the observation periods (Kalbfleisch and Prentice 1980).

Using the described approach, we estimate the median survival time of the startups $^{7}$ and the probability of failure after eight years to be 58 months and $63.4 \%$,

\footnotetext{
${ }^{6}$ The information about whether an exit occurred was taken from Companisto and the data platform Crowdinvest (2020)

7 The estimated median survival time is the number of months at which the estimated probability of failure is $50 \%$.
} 


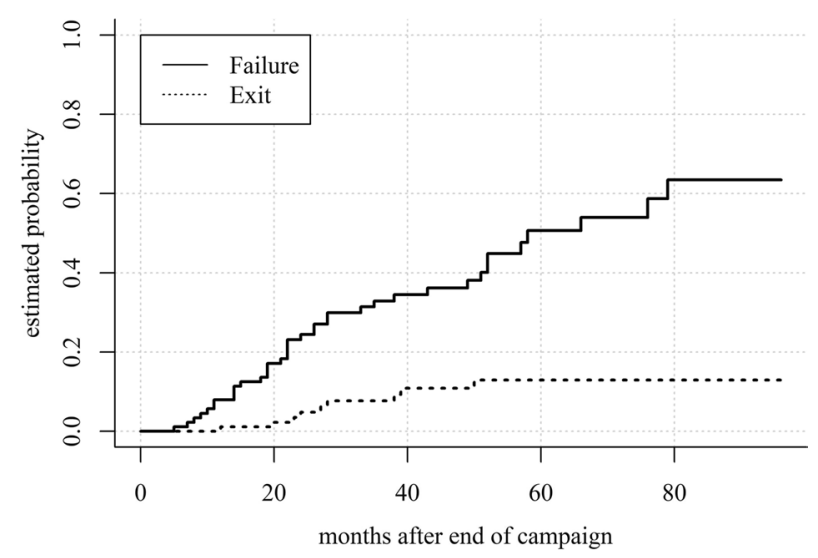

Fig. 2 Cumulative incidence functions of insolvencies and exits. The functions depict the estimated probability of the event have taken place until the end of the respective month after the successful crowdfunding campaign

respectively (Fig. 2). This exceeds both the failure rates of startups with venture capital support and those of startups in general (Puri and Zarutskie 2012). The probability of an exit in the period under consideration is estimated to be much lower at $13 \%$. These numbers highlight the importance of failures for the financial success of crowdfunding investments. Our study investigates which signals are associated with a lower risk of failure. It thus helps investors mitigate a complete loss of their investment. Furthermore, platforms and entrepreneurs can use validated signals to avoid adverse selection and market failure.

\section{Methods}

To investigate the relationship between survival probability and signals, we use logit models and Cox regression models (Cox 1972). The dependent variable in the logit regression is Failure, which indicates whether a startup has failed during the observation period. Logit analysis does not optimally use the censored data because it ignores the temporal structure. It treats failures after one year in the same way as it treats failures after eight years. However, although using a logit model leads to information loss, and therefore, loss of statistical power and precision, it may provide an easily understandable and good impression of the factors influencing the probability of failure. It is also helpful in comparing our results with those of other studies.

Cox regression is a semi-parametric procedure often used in clinical studies to investigate the association between survival time and predictor variables. The probability that an event will occur at a certain time is called the hazard, and the ratio of two time-dependent hazard functions is called the hazard ratio. In the present study, the considered hazard is a startup's failure. A hazard ratio below 1 indicates a covariate that is negatively related to the probability of failure, and thus, has a positive influence on venture success. The model by Cox (1972) is also called the proportional hazard model because it is based on the assumption that hazard ratios are constant over time (Hougaard 2000). We test this assumption using the Schoenfeld test (see Grambsch and 
Table 5 Overview on failures and censored data by years since the start of the campaign

\begin{tabular}{lllllll}
\hline $\begin{array}{l}\text { Year since } \\
\text { start of } \\
\text { campaign }(\mathbf{y})\end{array}$ & $\begin{array}{l}\text { \# startups } \\
\text { that survived } \\
\text { until the start } \\
\text { of } \mathbf{y}\end{array}$ & $\begin{array}{l}\text { \# failures in } \mathbf{y} \\
\text { yercentage } \\
\text { of failed } \\
\text { startups in } \mathbf{y}\end{array}$ & $\begin{array}{l}\text { \# failures } \\
\text { until the end } \\
\text { of } \mathbf{y}\end{array}$ & $\begin{array}{l}\text { \# censored } \\
\text { startups } \\
\text { in } \mathbf{y}\end{array}$ & $\begin{array}{l}\text { \# censored } \\
\text { startups until } \\
\text { the end of } \mathbf{y}\end{array}$ \\
\hline 1 & 88 & 2 & 2.27 & 2 & 0 & 0 \\
2 & 86 & 12 & 13.95 & 14 & 2 & 2 \\
3 & 72 & 11 & 15.28 & 25 & 13 & 15 \\
4 & 48 & 4 & 8.33 & 29 & 7 & 22 \\
5 & 37 & 5 & 13.51 & 34 & 11 & 33 \\
6 & 21 & 2 & 9.52 & 36 & 4 & 37 \\
7 & 15 & 2 & 13.33 & 38 & 4 & 41 \\
\hline
\end{tabular}

The first column contains the number of years since the start of the crowdfunding campaign. The third column shows the number of failures in year $y$, implying that two startups failed during the first year after the start of their campaign. In the next column, the ratio of these failures to the number of startups (column 2) is given. Column 5 contains the aggregated number of failures until the end of $y$. Censored startups during each year are given in column six. The last column presents the aggregated number of censored startups until the end of $y$

Therneau 1994). The advantage of Cox regression is that it considers the time until an event occurs and thus better utilizes the censored data.

To explain and illustrate the occurrence of censored data in our data set, Table 5 presents the number of available startups for each survival time in years. In the first months of the first year, all 88 startups can be considered. A total of 14 startups failed in the first two years after their respective campaigns started. The campaigns of two startups started less than two years before the end of our observation period, which is why they are censored when survival times of over two years are considered. After six years, 36 startups failed and 37 startups were censored, because their campaigns started less than seven years before the end of the observation period. Therefore, only 15 startups are considered when analyzing survival times of seven or more years. Cox regression compares startups that failed after a certain number of months with startups that survived at least that many number of months under the assumption of proportional hazards. The logit regression only distinguishes between startups that failed or did not fail during the observation period, regardless of the time passed since the start of their campaign. We use the variable Start campaign to control for the fact that startups whose campaigns started earlier had more time to fail. However, because Cox regressions are designed to use censored data, logit regression results should be interpreted primarily as robustness checks.

In logistic and Cox regressions, the number of events occurring is decisive for the potential number of variables to be tested (Vittinghoff and McCulloch 2007). Because our data set only contains 38 insolvencies, we keep the number of signals and control variables low. First, we estimate and report a model including all variables and controls (full model) using Cox regression. Then, we exclude variables in a stepwise manner, so that the Akaike information criterion (AIC) is minimized but all the variables of interest for our hypotheses are included. We report the resulting model with minimal AIC. Furthermore, we include the corresponding logit model. In addition, we report the results for the full model without industry dummies. 
Table 6 Base model

\begin{tabular}{|c|c|c|c|c|}
\hline Parameters & Full model & No industry dummies & Minimal AIC & Logit \\
\hline Degree (H1) & $0.40(0.64)$ & $0.31^{* *}(0.56)$ & $0.32^{* *}(0.48)$ & $-0.13(0.12)$ \\
\hline Equity offered (H2) & $0.89^{* * *}(0.04)$ & $0.90^{* * *}(0.04)$ & $0.90^{* * *}(0.04)$ & $-0.02^{* *}(0.009)$ \\
\hline Reputable investor backing (H3) & $0.65(0.53)$ & $0.53(0.47)$ & $0.47(0.46)$ & $-0.25^{* *}(0.12)$ \\
\hline$\#$ Invest5k (H4) & $1.04^{* *}(0.02)$ & $1.04^{* * *}(0.01)$ & $1.04^{* * *}(0.01)$ & $0.01^{* *}(0.005)$ \\
\hline \#Updates (H5) & $1.02(0.05)$ & $1.02(0.05)$ & $1.01(0.04)$ & $0.006(0.01)$ \\
\hline Start campaign & $1.09(0.16)$ & $0.97(0.14)$ & & $-0.09 * * *(0.03)$ \\
\hline Venture age & $0.85(0.13)$ & $0.89(0.12)$ & & \\
\hline Positive sales & $1.00(0.56)$ & $1.07(0.51)$ & & \\
\hline \#Investors & $1.00(0.00)$ & $1.00(0.00)$ & & \\
\hline Funding amount & $0.77(0.97)$ & $0.94(0.80)$ & & \\
\hline Target attainment & $0.54(0.57)$ & $0.43(0.52)$ & $0.35^{* *}(0.47)$ & $-0.29^{* *}(0.13)$ \\
\hline Big city & $0.69(0.55)$ & $0.68(0.52)$ & & \\
\hline Business value & $0.94(0.08)$ & $0.94(0.07)$ & $0.90^{* *}(0.05)$ & $-0.029 *(0.02)$ \\
\hline Industry experience & $0.51^{*}(0.39)$ & $0.56(0.38)$ & $0.52^{*}(0.37)$ & $-0.22^{* *}(0.09)$ \\
\hline Management size & $0.92(0.15)$ & $0.91(0.14)$ & & \\
\hline Entrepreneurial company & $2.75^{*}(0.60)$ & $3.03 *(0.58)$ & $3.09^{* *}(0.55)$ & $0.35^{*}(0.19)$ \\
\hline Follow-up campaign & $5.09^{* *}(0.81)$ & $4.64^{*}(0.81)$ & $3.03(0.72)$ & $0.14(0.16)$ \\
\hline Industry dummies & Yes & No & Yes & Yes \\
\hline Observations & 88 & 88 & 88 & 88 \\
\hline Concordance & 0.750 & 0.715 & 0.716 & 0.809 \\
\hline$R^{2}$ & 0.105 & 0.089 & 0.083 & 0.288 \\
\hline
\end{tabular}

The values in the first three models of the table are the estimated hazard ratios, the standard errors of the natural logarithm of the hazard ratios are given in parentheses. The full model includes all variables. In "no industry dummies" industry dummies are excluded. "Minimal AIC" represents a model obtained by stepwise exclusion of variables, so that the AIC is minimized but all variables of interest for our hypotheses are included. "Logit" contains the estimated AMEs (standard errors in parentheses) using a logit model and the variables of Minimal AIC plus Start campaign. We use McFadden's R-squared for the Cox models and Tjur's R-squared for the logit model. Number of events: 38 failures

* $p<0.1$; ${ }^{* *} p<0.05$; ${ }^{* * *} p<0.01$

\section{Results}

In this section, we present the results according to the hypotheses. Table 6 reports the results of the base model. As explained above, we show the results of the full model using all the variables, the model without industry dummies, the model with minimal AIC, and the corresponding logit model. The logit model always includes the control variable Start campaign. To enable interpretation in percentage points, the column "Logit" provides the average marginal effects. The AME of a variable is computed as the average of its marginal effect for each observation. Thus, it provides an estimate of the average impact of a one-unit change in the variable on the probability of failure. We further report Tjur's R-squared (Tjur 2009) and concordance to quantify the quality of fit of the logit models. Concordance is defined as the probability of the prediction going in the same direction as the actual data (Harrell et al. 1996). In our model, a pair of observations is considered concordant if the startup with the higher estimated probability of failure fails and the other does not. The pair is considered discordant for the vice-versa. Concordance is calculated as the fraction of concordant pairs, meaning that a value of 0.5 corresponds to random guesses. According to Therneau and Atkinson (2020), it is the most used measure of goodness-of-fit in survival models. 
The fit of the Cox regressions is quantified using the concordance and McFadden's R-squared (McFadden 1987). This pseudo R-squared is calculated as $1-\frac{\log \left(\mathrm{L}_{1}\right)}{\log \left(\mathrm{L}_{0}\right)}$, where $\log \left(\mathrm{L}_{1}\right)$ and $\log \left(\mathrm{L}_{0}\right)$ depict the $\log$-likelihood of the considered model and $\log \left(\mathrm{L}_{0}\right)$ the log-likelihood of a model with only an intercept. The values of R-squared in our models range from 0.083 to 0.105 and are thus comparable to the pseudo R-squared value of 0.077 reported by Hornuf et al. (2018). Furthermore, all the concordances exceed 0.7 , indicating a good fit. In the logit model, Tjur's R-squared is relatively high with a value of 0.288 , compared to the pseudo R-squared value of 0.13 in Hornuf et al. (2018). This is similar to the pseudo R-squared value of 0.33 reported by Signori and Vismara (2018). ${ }^{8}$ The concordance of approximately 0.8 also indicates that the model is a good fit.

The estimated hazard ratios appear to be stable across all three Cox models. This suggests that no major problems occur due to a low number of events per variable. Furthermore, the Schoenfeld test using the model with minimal AIC yields a p-value of 0.25, and the Schoenfeld residuals for each variable do not show a pattern in time. This indicates no significant violation of the proportional hazard assumption.

\section{University degree $(\mathrm{H} 1)$}

We find evidence for H1, i.e. the positive influence of the CEO's university degree. The estimated hazard ratio for Degree (H1) ranges from 0.31 to 0.40 and is statistically significant in the model with minimal AIC. The values imply that the risk of failure for startups, which indicated their CEO's university degree during the crowdfunding campaign, are 60 to $69 \%$ lower than for the startups that did not signal a degree. In the logit regression, the AME amounts to -0.13 , which also implies that indicating a degree is likely to reduce the risk of failure. However, the effect is statistically insignificant, which can be partly attributed to the high information loss caused from not using the temporal structure of our long data set.

Interestingly, and contrary to the findings of Piva and Rossi-Lamastra (2018) on investor behavior, we do not find a special influence of an economics degree. This could be interpreted to mean the experience and networks acquired during the educational period are more important for avoiding failure than the acquired economic skills themselves. ${ }^{9}$ However, in this study, we only capture the education of the CEO as the most important actor. In future studies with more data, more human capital signals can be investigated as potential quality signals.

Note that we use Industry experience, which indicates if the CEO has stated that they have work experience in the industry of the startup, as a control variable. Industry experience is associated with a smaller risk of failure in the Cox and logit regressions, indicating that industry experience may be a relevant signal of venture quality.

\footnotetext{
${ }^{8}$ Note that Hornuf et al. (2018) or Signori and Vismara (2018) do not state which R-squared they use. As McFadden's $\mathrm{R}$-squared is the default in Stata, we assume it is McFadden's R-squared. The R-squared values according to McFadden for our models are larger than the corresponding values of Tjur's R-squared and also exceed the value of 0.13 reported by Hornuf et al. (2018).

9 To test for an additional effect of an economics degree, we run the AIC-minimizing regression by adding of a dummy variable that indicates whether the CEO holds an economics degree. The corresponding coefficient is insignificant with a high p-value of over 0.75 .
} 


\section{Equity offered (H2)}

The estimated hazard ratios of Equity offered (H2) are statistically significant and range from 0.89 to 0.90 . This means that an increase in equity shares offered by one percent point yields a reduction of $10 \%$ in risk of failure. Since the SD of Equity offered is 6.96, an increase of one SD would thus reduce the risk of failure by approximately half. The effect, therefore, is of high economic significance. The logit model shows a similar effect. The AME amounts to -0.02 , implying that increasing the equity share offered by one percent point reduces the probability of failure by over two percentage points on average. We can, therefore, reject $\mathbf{H} 2$, i.e. the positive influence of low equity stakes offered on venture success, and we find an effect in the opposite direction, which is statistically significant in all logit and Cox regressions. This contradicts the findings of Cumming et al. (2019) for data from the UK that a smaller level of equity offered in the crowdfunding campaign is positively linked to the likelihood of success and negatively linked to the probability of failure. They conclude that the increased interest alignment between controlling shareholders and investors, which is measured by retained equity, reduces the probability of failure. Their result suggests that investors can reasonably interpret low offered participation rates as a positive signal. However, our findings using German data indicate a significant effect in the opposite direction. Therefore, crowdfunding investors in Germany should not interpret low offered participation rates as a signal for a higher probability of survival. Note that Hornuf et al. (2018) report a significant positive effect of shares offered on survival probability in an additional specification of their model as well. Interestingly, their data set contains $65 \%$ campaigns from UK portals, for which Cumming et al. (2019) found opposite effects in a later study. Our finding indicates that the difference in results between Hornuf et al. (2018) and Cumming et al. (2019) could be explained by the fact that the equity shares offered in Germany play a different role than in other countries. This may be because a special feature of the German equity-based crowdfunding market is the usage of mezzanine capital, such as participatory loans ("partiarische Darlehen"), instead of shares, which does not dilute the founders' voting rights via crowdfunding. Furthermore, offering a high equity stake also means that, after financing, a high proportion of the venture value consists of liquid funds, which should help avoid illiquidity in subsequent years.

\section{Reputable investor backing $(\mathrm{H} 3)$}

We cannot confirm H3, i.e. the positive effect of reputable investors supporting the venture before the campaign, even though the logit model suggests a significant positive effect. However, although the hazard ratios are below one in all the regressions, they are statistically insignificant. This may partly be due to the small sample size or variance inflation emerging from the correlations between independent variables. However, there are other possible explanations. First, reputable investors might specifically select ventures that have a higher risk of failure but can potentially yield higher returns if they survive (Capizzi and Carluccio 2016). Second, and in line with Mollick and Nanda (2015), who find no significant differences between projects that are only funded by the crowd and those that are also selected by experts, the crowd might be equally good (or bad) at separating good from bad projects. 
Table 7 Model including backing by different reputable investor types

\begin{tabular}{|c|c|c|c|c|}
\hline Parameters & Full model & No industry dummies & Minimal AIC & Logit \\
\hline Degree & $0.33(0.69)$ & $0.27^{* *}(0.59)$ & $0.37^{*}(0.53)$ & $-0.01(0.12)$ \\
\hline Equity offered & $0.89^{* *}(0.05)$ & $0.91^{* *}(0.04)$ & $0.92^{* *}(0.03)$ & $-0.01(0.008)$ \\
\hline BA backing & $0.85(0.51)$ & $0.69(0.48)$ & $0.82(0.48)$ & $-0.14(0.11)$ \\
\hline VC backing & $3.14^{* *}(0.58)$ & $2.08(0.54)$ & $3.22^{* *}(0.53)$ & $0.25^{* *}(0.12)$ \\
\hline Other investors backing & $0.98(0.65)$ & $0.83(0.59)$ & $0.87(0.59)$ & $-0.03(0.13)$ \\
\hline \#lnvest5k & $1.04^{* *}(0.02)$ & $1.04^{* * *}(0.01)$ & $1.02^{* * *}(0.01)$ & $0.005^{* *}(0.003)$ \\
\hline \#Updates & $0.99(0.05)$ & $1.00(0.05)$ & $0.99(0.05)$ & $0.0008(0.01)$ \\
\hline Start campaign & $1.07(0.16)$ & $0.94(0.15)$ & & $-0.07^{* * *}(0.03)$ \\
\hline Venture age & $0.81(0.15)$ & $0.88(0.13)$ & $0.80 *(0.12)$ & $-0.04(0.025)$ \\
\hline Positive sales & $0.93(0.58)$ & $0.98(0.52)$ & & \\
\hline \#Investors & $1.00(0.00)$ & $1.00(0.00)$ & & \\
\hline Funding amount & $0.67(1.09)$ & $0.81(0.84)$ & & \\
\hline Target attainment & $0.76(0.55)$ & $0.52(0.51)$ & & \\
\hline Big city & $0.61(0.55)$ & $0.61(0.54)$ & & \\
\hline Business value & $0.95(0.08)$ & $0.95(0.07)$ & & \\
\hline Industry experience & $0.55(0.39)$ & $0.62(0.37)$ & $0.55(0.37)$ & $-0.21^{* *}(0.09)$ \\
\hline Management size & $0.89(0.13)$ & $0.91(0.13)$ & & \\
\hline Entrepreneurial company & $3.36^{*}(0.63)$ & $3.60^{* *}(0.59)$ & $2.55^{*}(0.55)$ & $0.27(0.17)$ \\
\hline Follow-up campaign & $3.64(0.85)$ & $3.08(0.87)$ & & \\
\hline Industry dummies & Yes & No & Yes & Yes \\
\hline Observations & 88 & 88 & 88 & 88 \\
\hline Concordance & 0.776 & 0.720 & 0.752 & 0.812 \\
\hline$R^{2}$ & 0.116 & 0.090 & 0.096 & 0.291 \\
\hline \multicolumn{5}{|c|}{$\begin{array}{l}\text { The values in the first three models of the table are the estimated hazard ratios, the standard errors of the natural logarithm } \\
\text { of the hazard ratios are given in parentheses. The full model includes all variables. In "no industry dummies" industry } \\
\text { dummies are excluded. "Minimal AIC" represents a model obtained by stepwise exclusion of variables, so that the AIC is } \\
\text { minimized but all variables of interest for our hypotheses are included. "Logit" contains the estimated AMEs (standard errors } \\
\text { in parentheses) using a logit model and the variables of Minimal AIC plus Start campaign. We use McFadden's R-squared for } \\
\text { the Cox models and Tjur's R-squared for the logit model. Number of events: } 38 \text { failures }\end{array}$} \\
\hline \multicolumn{5}{|c|}{${ }^{*} p<0.1 ; * * p<0.05 ; * * * p<0.01$} \\
\hline
\end{tabular}

To examine whether backing by different types of professional investors has different effects on failure rates, Tables 7 and 8 present regression results with a finer categorization into BAs, VCs, and other investors. In Table 7, we examine whether the startup is backed by investors from the respective category using dummy variables. In Table 8, we consider the number of investors backing the startup.

While backing by BAs appears to have a positive effect on the risk of failure, backing by VCs is associated with a higher risk of failure. The negative effect of VCs on startup survival is in line with the finding of Hornuf et al. (2018) that the number of initial VC investors is negatively related to firm survival.

Note that we also tested whether the number of actual investments by corporations during the crowdfunding campaign affects the risk of failure. However, there is no significant effect, which is why we have not reported the regression results.

\section{Large investments $(\mathrm{H} 4)$}

H4, i.e. the positive effect of large investments on venture success, can be rejected as well. In all the regressions, we find hazard ratios above one, which are statistically significant, implying that large investments are positively related to the probability of failure, 
Table 8 Regression model including the number of reputable investors backing the startup by type

\begin{tabular}{lllll}
\hline Parameters & Full model & No industry dummies & Minimal AIC & Logit \\
\hline Degree & $0.35^{*}(0.62)$ & $0.25^{* *}(0.55)$ & $0.28^{* * *}(0.48)$ & $-0.19(0.12)$ \\
Equity offered & $0.86^{* * *}(0.06)$ & $0.89^{* *}(0.05)$ & $0.88^{* * *}(0.04)$ & $-0.02^{* *}(0.009)$ \\
\#BA & $0.93(0.05)$ & $0.97(0.04)$ & $0.98(0.04)$ & $0.02(0.03)$ \\
\#VC & $1.58(0.30)$ & $1.34(0.27)$ & $1.38(0.26)$ & $0.08(0.06)$ \\
\#Other investors & $1.57(0.40)$ & $1.33(0.37)$ & $1.45(0.36)$ & $0.08(0.08)$ \\
\#Invest5k & $1.05^{* * *}(0.02)$ & $1.04^{* * *}(0.01)$ & $1.04^{* * *}(0.01)$ & $0.01^{* *}(0.005)$ \\
\#Updates & $0.97(0.06)$ & $0.99(0.05)$ & $0.99(0.05)$ & $-0.0025(0.01)$ \\
Start campaign & $1.10(0.17)$ & $0.94(0.15)$ & & $-0.07^{* * *}(0.03)$ \\
Venture age & $0.72^{*}(0.19)$ & $0.85(0.14)$ & $0.85(0.13)$ & $-0.02(0.03)$ \\
Positive sales & $1.00(0.58)$ & $1.09(0.52)$ & & \\
\#Investors & $1.00(0.00)$ & $1.00(0.00)$ & & \\
Funding amount & $1.09(1.07)$ & $1.00(0.87)$ & $0.48(0.54)$ & $-0.26^{* *}(0.13)$ \\
Target attainment & $0.48(0.64)$ & $0.40(0.56)$ & & \\
Big city & $0.57(0.55)$ & $0.60(0.54)$ & $0.90(0.06)$ & $-0.03(0.02)$ \\
Business value & $0.89(0.09)$ & $0.90(0.08)$ & $0.56(0.36)$ & $-0.20^{* *}(0.09)$ \\
Industry experience & $0.50^{*}(0.39)$ & $0.62(0.36)$ & & \\
Management size & $0.90(0.15)$ & $0.91(0.14)$ & $2.96^{*}(0.57)$ & $0.37^{* *}(0.18)$ \\
Entrepreneurial company & $2.97^{*}(0.61)$ & $3.51^{* *}(0.58)$ & $4.26^{* *}(0.73)$ & $0.09(0.18)$ \\
Follow-up campaign & $6.04^{* *}(0.82)$ & $4.51^{*}(0.79)$ & Yes & Yes \\
Industry dummies & Yes & No & 88 & 88 \\
Observations & 88 & 88 & 0.757 & 0.815 \\
Concordance & 0.773 & 0.731 & 0.091 & 0.306 \\
R 2 & 0.120 & & & \\
\hline The valuesinte & & & & \\
\hline
\end{tabular}

The values in the first three models of the table are the estimated hazard ratios, the standard errors of the natural logarithm of the hazard ratios are given in parentheses. The full model includes all variables. In "no industry dummies" industry dummies are excluded. "Minimal AIC" represents a model obtained by stepwise exclusion of variables, so that the AIC is minimized but all variables of interest for our hypotheses are included. "Logit" contains the estimated AMEs (standard errors in parentheses) using a logit model and the variables of Minimal AIC plus Start campaign. We use McFadden's R-squared for the Cox models and Tjur's R-squared for the logit model. Number of events: 38 failures

${ }^{*} p<0.1 ;{ }^{* *} p<0.05 ;{ }^{* * *} p<0.01$

and thus, negatively to venture success. \#Invest5k significantly increases the probability of failure by approximately $4 \%$ per additional large investment in all models. Considering that the SD of \#Invest5k of 27.62, this effect is economically significant as well, as an increase by one SD roughly triples the risk of failure. The effect is consistent with the positive and significant AME in the logit model.

Imitating investors who have invested high amounts thus does not seem worthwhile. A possible explanation might be that some of these investors do not have financial motives at all because they could be part of the founders' personal network ("friends and family", see Agrawal et al. 2015). Another explanation is that large investments might be used strategically to induce herding behavior via information cascades (Vismara 2018a). This may dilute or even reverse the signal of large investments. Furthermore, large investments by a single investor could signify high risk tolerance. In such cases, these investors could deliberately select particularly risky projects which, if successful, would yield exceptionally high returns. Future research could test this explanatory approach, for example, by investigating whether large investments are 
Table 9 Model with differentiation between large private and corporate investments

\begin{tabular}{lllll}
\hline Parameters & Full model & No industry dummies & Minimal AIC & Logit \\
\hline Degree & $0.41(0.65)$ & $0.31^{* *}(0.56)$ & $0.35^{* *}(0.47)$ & $-0.11(0.13)$ \\
Equity offered & $0.89^{* * *}(0.04)$ & $0.90^{* *}(0.04)$ & $0.91^{* *}(0.04)$ & $-0.02^{* *}(0.01)$ \\
Reputable investor backing & $0.66(0.53)$ & $0.53(0.47)$ & $0.51(0.45)$ & $-0.23^{*}(0.12)$ \\
\#Invest5k private & $1.04^{* *}(0.02)$ & $1.04^{* *}(0.02)$ & $1.04^{* *}(0.01)$ & $0.01^{* *}(0.006)$ \\
\#Invest5k corporate & $1.05(0.18)$ & $1.01(0.16)$ & $1.04(0.14)$ & $0.02(0.04)$ \\
\#Updates & $1.01(0.05)$ & $1.02(0.05)$ & $0.99(0.04)$ & $0.003(0.01)$ \\
Start campaign & $1.11(0.16)$ & $0.97(0.14)$ & & $-0.08^{* * *}(0.03)$ \\
Venture age & $0.85(0.13)$ & $0.89(0.12)$ & & \\
Positive sales & $1.00(0.56)$ & $1.07(0.51)$ & & \\
\#Investors & $1.00(0.00)$ & $1.00(0.00)$ & & \\
Funding amount & $0.76(0.98)$ & $0.91(0.81)$ & $0.41^{* *}(0.46)$ & $-0.29^{* *}(0.13)$ \\
Target attainment & $0.55(0.57)$ & $0.44(0.52)$ & & \\
Big city & $0.70(0.55)$ & $0.69(0.52)$ & $0.92^{*}(0.05)$ & $-0.03^{*}(0.02)$ \\
Business value & $0.94(0.08)$ & $0.94(0.07)$ & $0.51^{*}(0.37)$ & $-0.22^{* *}(0.09)$ \\
Industry experience & $0.50^{*}(0.40)$ & $0.56(0.38)$ & & \\
Management size & $0.91(0.15)$ & $0.91(0.14)$ & $2.85^{*}(0.55)$ & $0.34^{*}(0.19)$ \\
Entrepreneurial company & $2.69(0.62)$ & $2.96^{*}(0.59)$ & & \\
Follow-up campaign & $4.99^{* *}(0.81)$ & $4.68^{*}(0.82)$ & Yes & Yes \\
Industry dummies & Yes & No & 87 & 87 \\
Observations & 87 & 87 & 0.075 & 0.807 \\
Concordance & 0.750 & 0.720 & 0.275 \\
R 2 & 0.105 & 0.089 & & \\
\hline The & 5.707 & & \\
\hline
\end{tabular}

The values in the first three models of the table are the estimated hazard ratios, the standard errors of the natural logarithm of the hazard ratios are given in parentheses. The full model includes all variables. In "no industry dummies" industry dummies are excluded. "Minimal AIC" represents a model obtained by stepwise exclusion of variables, so that the AIC is minimized but all variables of interest for our hypotheses are included. "Logit" contains the estimated AMEs (standard errors in parentheses) using a logit model and the variables of Minimal AIC plus Start campaign. We use McFadden's R-squared for the Cox models and Tjur's R-squared for the logit model. Number of events: 38 failures

${ }^{*} p<0.1 ;{ }^{* *} p<0.05 ;{ }^{* * *} p<0.01$

positively related to the exit probability or the returns in the event of an exit (and thus the overall expected return).

Table 9 presents the results of the regressions in which we differentiated large investments made by corporations (as a proxy for professional investors) and those by private individuals. Large investments by corporations, on average, still have a negative effect. However, it is statistically insignificant with high p-values. Thus, large investments by private individuals seem to be a negative signal; regarding large investments by corporations, a clear conclusion cannot be drawn from the data.

Note that we ran several robustness checks. Defining large investments as investments of at least $€ 10,000$ or $1 \%$ of the demanded funding amount and using the total amount of investments of at least $€ 5,000$ yields qualitatively similar results.

\section{Updates (H5)}

\#Updates has no significant effect in any of the regressions. The generally positive crowd response to updates, as found in Hornuf and Schwienbacher (2018) and Bade and Walther (2021), is not accompanied by a better post-offering performance. Thus, we cannot confirm H5. 
Table 10 Model with categorization of updates

\begin{tabular}{|c|c|c|c|c|}
\hline Parameters & Full model & No industry dummies & Minimal AIC & Logit \\
\hline Degree & $0.89(0.81)$ & $0.49(0.66)$ & $0.54(0.51)$ & $0.052(0.12)$ \\
\hline Equity offered & $0.80^{* * *}(0.06)$ & $0.82^{* * *}(0.05)$ & $0.84^{* * *}(0.05)$ & $-0.03^{* * *}(0.01)$ \\
\hline Reputable investor backing & $0.39(0.72)$ & $0.43(0.64)$ & $0.41^{*}(0.55)$ & $-0.27^{* *}(0.13)$ \\
\hline \#Invest5k & $1.05(0.03)$ & $1.04(0.02)$ & $1.05^{* * *}(0.01)$ & $0.01^{* *}(0.005)$ \\
\hline \#Upd. campaign development & $1.41^{* *}(0.14)$ & $1.48^{* * *}(0.14)$ & $1.37^{* * *}(0.12)$ & $0.11^{* * *}(0.03)$ \\
\hline \#Upd. business developments & $0.69(0.24)$ & $0.70(0.24)$ & $0.66^{* *}(0.17)$ & $-0.05(0.04)$ \\
\hline \#Upd. new funding & $0.92(0.36)$ & $0.94(0.34)$ & & \\
\hline \#Upd. cooperation projects & $0.62(0.30)$ & $0.68(0.24)$ & $0.78(0.19)$ & $-0.06^{*}(0.04)$ \\
\hline \#Upd. ext. certification & $2.11^{* * *}(0.27)$ & $1.98^{* * *}(0.23)$ & $2.11^{* * *}(0.21)$ & $0.11^{* *}(0.04)$ \\
\hline \#Upd. team & $1.99(0.44)$ & $2.02 *(0.38)$ & $2.14^{* *}(0.32)$ & $-0.035(0.08)$ \\
\hline \#Upd. business model & $0.29^{* *}(0.51)$ & $0.31^{* * *}(0.44)$ & $0.34^{* * *}(0.35)$ & $-0.11^{*}(0.06)$ \\
\hline \#Upd. product development & $1.26(0.21)$ & $1.19(0.16)$ & & \\
\hline \#Upd.promotions & $1.31(0.19)$ & $1.26(0.18)$ & $1.26^{*}(0.14)$ & $0.04(0.03)$ \\
\hline \#Upd. others & $0.69(0.34)$ & $0.82(0.29)$ & & \\
\hline Start campaign & $1.38(0.21)$ & $1.18(0.18)$ & & $-0.08^{* * *}(0.04)$ \\
\hline Venture age & $0.98(0.18)$ & $0.99(0.16)$ & & \\
\hline Positive sales & $2.26(0.74)$ & $2.63(0.67)$ & $2.36(0.56)$ & $0.31^{* *}(0.14)$ \\
\hline \#Investors & $1.00(0.00)$ & $1.00(0.00)$ & & \\
\hline Funding amount & $0.64(1.71)$ & $1.14(1.52)$ & & \\
\hline Target attainment & $0.13^{* *}(0.81)$ & $0.12^{* * *}(0.74)$ & $0.13^{* * *}(0.59)$ & $-0.48^{* * *}(0.13)$ \\
\hline Big city & $1.41(0.73)$ & $1.64(0.69)$ & & \\
\hline Business value & $0.79^{* *}(0.10)$ & $0.79^{* * *}(0.09)$ & $0.81^{* * *}(0.06)$ & $-0.04^{* *}(0.02)$ \\
\hline Industry experience & $0.28^{* *}(0.58)$ & $0.37^{* *}(0.49)$ & $0.44^{*}(0.43)$ & $-0.23^{* *}(0.10)$ \\
\hline Management size & $0.99(0.19)$ & $0.94(0.18)$ & & \\
\hline Entrepreneurial company & $1.45(0.87)$ & $1.50(0.80)$ & & \\
\hline Follow-up campaign & $5.99 *(1.05)$ & $6.71 *(1.07)$ & $6.53^{* *}(0.78)$ & $0.26(0.17)$ \\
\hline Observations & 88 & 88 & 88 & 88 \\
\hline Concordance & 0.846 & 0.846 & 0.824 & 0.888 \\
\hline$R^{2}$ & 0.189 & 0.192 & 0.176 & 0.449 \\
\hline
\end{tabular}

The values in the first three models of the table are the estimated hazard ratios, the standard errors of the natural logarithm of the hazard ratios are given in parentheses. The full model includes all variables. In "no industry dummies" industry dummies are excluded. "Minimal AIC" represents a model obtained by stepwise exclusion of variables, so that the AIC is minimized but all variables of interest for our hypotheses are included. "Logit" contains the estimated AMEs (standard errors in parentheses) using a logit model and the variables of Minimal AIC plus Start campaign. We use McFadden's R-squared for the Cox models and Tjur's R-squared for the logit model. Number of events: 38 failures

${ }^{*} p<0.1$; ${ }^{* *} p<0.05 ;{ }^{* * *} p<0.01$

However, by categorizing updates, Block et al. (2018a) find that the effect on investor engagement also varies depending on the update's content. To test whether the effects on post-offering success are consistent with their findings on campaign success, we use the same categorization of updates. The results are presented in Table 10.

Several variables are statistically significant. The number of updates on campaign developments, external certification, team, and promotions is associated with a higher risk of failure in the minimal AIC model. In contrast, the number of updates on business developments, cooperation projects, and the business model is associated with a lower risk of failure. These results are consistent with the main conclusion of Block et al. (2018a) who find that the crowd is particularly sensitive to businessrelated information such as business development or cooperation projects. They also 
report a negative effect of updates on external certification on crowd participation. However, crowd participation increases after an update on campaign development. This contrasts our finding that a higher number of updates on campaign development is associated with a higher risk of failure. This suggests that the crowd may be overly influenced by campaign development, possibly resulting in herding behavior. The number of updates on promotions and the team have a significant impact on postoffering success but are insignificant in Block et al. (2018a).

Overall, updates on business-related information, such as business developments and the business model, appear to be interpreted as positive signals regarding the risk of failure. In contrast, the number of updates on external certification, promotions, and the team is associated with a higher risk of failure and, therefore, should be considered as negative signals.

Note that we also ran the regression using the total number of updates and the percentages of updates for the respective type. The qualitative results are comparable.

\section{Other variables}

In addition to the variables relevant to the hypotheses, Venture age, Business value, Target attainment, Follow-up campaign, Industry experience, and the legal form (Entrepreneurial company) appear to be the most important factors. Younger and smaller ventures are more likely to fail, which is in line with the liability of newness and smallness discussed above. Ventures that have the legal form "entrepreneurial company," on average, have a much higher risk of failure. Therefore, the choice of a legal form with low liability appears to signal low venture quality. Startups, in which the CEO indicated that they have experience in the industry of the startup, are less likely to fail. Thus, the industry experiences of the CEO might be a signal of high venture quality. Furthermore, failure rates are higher if the venture has previously ran another crowdfunding campaign. Multiple crowdfunding campaigns seem to signal low venture quality, as it could imply a lack of interest from other investors. The other controls have statistically insignificant effects.

\section{Discussion}

In this section, we discuss the implications and limitations of the results.

\section{Implications}

Our study investigates whether the crowd follows the correct signals, i.e. it examines whether information that has an effect on campaign success is actually followed by a higher post-offering success. We find that the crowd partly uses wrong signals.

First, we find that the total number of updates during the crowdfunding campaign has no significant effect on the risk of failure. This indicates that investors should not consider a high total number of updates as a quality signal. We find that the update's content is decisive for its effect on the risk of failure. A higher number of business-related updates is associated with a lower risk of failure. The number of updates on external certification, promotions, and the team is associated with a higher risk of failure. These results are reasonably consistent with crowd behavior as reported by Block et al. (2018a). However, according to Block et al. (2018a), updates on campaign development increase 
crowd participation significantly. We find that a high number of such updates is associated with a higher risk of failure. Thus, updates on campaign development increase crowd participation by drawing attention to the campaign. Investors should, therefore, prefer startups that use updates to communicate relevant business information over startups that primarily try to draw attention to their campaign.

Second, the number of large investments during a campaign appears to have a negative effect on startup survival. This contradicts the positive effect of large investments on the number of investments and their size on Companisto (Hornuf and Schwienbacher 2018; Walther and Bade 2020). Our finding indicates that large investments might have led to information cascades and consequently, inefficient investments. Investors who invest large amounts into a campaign may have non-financial motives as they may be from the social network of the entrepreneurs. In this case, the large investment is not from a sophisticated investor who has procured information and assessed the chances of success as promising. Large investments can, therefore, be easily misinterpreted by other crowdfunding investors. Our result emphasizes the importance of the regulation of large investments to prevent information cascades. Misinterpretations of large investments could be reduced if platforms provide information on the level of sophistication and (professional) investing experience of crowd investors. For example, platforms could provide investors with the opportunity to state their profession. Furthermore, the maximum amount that may be invested could made dependent on the professionalism or investment experience of the investor. However, limiting access to investment opportunities for less-sophisticated investors contradicts the notion of democratizing equitybased crowdfunding (Cumming et al. 2021). Furthermore, strong regulations could harm the ability of startups to bridge the early-stage funding gap and also reduce the attractiveness of equity crowdfunding (Hornuf and Schwienbacher 2017). This harsh measure should, therefore, only be taken if providing further information turns out to be insufficient.

Third, we find that the percentage of equity shares offered is negatively related to the probability of startup failure. This contradicts the recent finding by Cumming et al. (2019), using data from the UK, that equity retention is positively related to post-offering success. As Companisto brokered participatory loans without voting rights instead of shares, our contrary result suggests that the type of financial instrument used by the crowdfunding platform is decisive for the behavior of risk of failure with respect to the equity shares offered during the crowdfunding campaign.

Regarding updates on campaign development, large investments and equity shares offered the crowd thus follows signals that lead to a worse subsequent performance. These results challenge the wisdom of the crowd. Furthermore, it raises the question of whether the screening carried out by the platform, the signaling performed by the startups, and the wisdom of the crowd are enough for small private investors to overcome information asymmetries. The high failure rates and the change in the focus of Companisto's business model from mainly small investors to accredited investors highlight this great challenge facing equity-based crowdfunding.

As for the other studied signals, the behavior of the crowd and post-offering success appear to be aligned. Thus, credible signals that entrepreneurs can send include indicating their university degree, indicating relevant industry experiences, and not choosing a 
legal form with low liability. Backing by reputable investors, although statistically insignificant in most of our models, might have a rather positive effect on post-offering success. Obtaining (and stating) support from reputable investors might, therefore, not only increase the crowd's willingness to invest, but also have a positive effect on post-offering success. For entrepreneurs, the effort of acquiring such supporters could, therefore, be worthwhile. Upon classifying reputable investors into BAs, VCs, and other investors, we find that BAs are associated with a lower risk of failure, while startups with backing by VCs have a higher risk of failure. Therefore, investors with low risk tolerance should not base their investment decisions on backing by VCs.

Our analysis can also be valuable for other investors in later financing rounds, such as venture capitalists, as they can use our results on signals generated during the crowdfunding campaign to better assess failure risks.

\section{Limitations}

Our study has some limitations. First, we do not separately analyze the effects of signaling a university degree, the equity shares offered, reputable investor backing, the number of large investments, and the number of updates on offering success. Instead, we rely on the results of other studies and assume that investors on Companisto show a similar investment behavior as those in the studies considered. However, the considered studies, for example, on the effects of updates and large investments on the investments of the crowd, use data sets including a large proportion of campaigns from Companisto (Hornuf and Schwienbacher 2018; Walther and Bade 2020).

Moreover, due to the lack of more available data, our data set contains only $88 \mathrm{cam}$ paigns. This leads to higher standard errors that reduce the statistical power of our analysis. However, although the number of campaigns considered is smaller than in some recent studies on post-offering outcomes, the number of events (failures) is on a similar level: Hornuf et al. (2018) investigate a data set of 413 campaigns from 13 platforms over seven years. A total of 143 campaigns (from eleven platforms) were conducted in Germany. In their data set, 69 insolvencies occurred in total, 39 of which were in Germany. For Germany, the event numbers are, therefore, comparable. Cumming et al. (2019) consider 491 campaigns over five years from one platform (Crowdcube). They report that 45 firms had long-term success, while 31 failed. Signori and Vismara $(2016,2018)$ consider 212 offerings from Crowdcube. Their data sets contain 22 and 38 failures, respectively. The sample of Hornuf et al. (2020) consists of 74 campaigns (31 insolvencies) from two platforms over five years. The latter study requires very specific information (the locations of investors), which is why the number of observations is low.

We encounter a similar difficulty as Hornuf et al. (2020) in collecting data. Some of our variables, particularly the number of large investments, are not available on all platforms. Therefore, we only use data from Companisto. However, focusing on one platform has the advantage that all campaigns are comparable. As indicated by the large difference in failure rates between startups from Germany and the UK in Hornuf et al. (2018), the probabilities of failure can differ greatly across platforms. Platforms have different levels of reputation, different selection mechanisms for campaigns, and different audiences. As we use data from only one platform in our study, we do not face this problem. Thus, we 
do not need platform dummies and possible interactions between them and the variables of interest, which is an advantage of our data set. Furthermore, Companisto has fundamentally changed its approach to campaigns, making our data set a closed data set.

Overall, our number of observations is smaller than in recent comparable studies. However, the number of events, which is decisive for the number of variables that can be tested (Vittinghoff and McCulloch 2007), is on a similar level. Moreover, due to the heterogeneity between countries and platforms, particularly in terms of the financial instruments used, the aggregation of data from several platforms can be problematic. The investigation of a long observation period (more than eight years) with comparable campaigns can, therefore, also be seen as an advantage. ${ }^{10}$

We could only analyze failure probabilities because the number of exits is small, and we cannot, therefore, examine the return on investment.

Another limitation is that we cannot rule out the possibility that multicollinearity between variables might inflate standard errors. However, the estimates in our models are robust to excluding variables. Therefore, we think that multicollinearity should not be a major issue.

Our main results on the equity shares offered and the number of large investments are statistically and economically significant. Therefore, our results can, despite these limitations, make a relevant contribution to equity-based crowdfunding literature by identifying signals that are used by the crowd but are likely to be misinterpreted.

\section{Summary}

This study investigates the relationship between the signals generated during equity crowdfunding campaigns and subsequent venture success, measured as the probability of survival. Using a hand-collected comprehensive data set of campaigns on a large German crowdfunding platform and logit and Cox regression models, we consider the effects of stating that the CEO holds a university degree, the equity stake offered, backing by reputable investors, the number of large investments, and updates during the campaign. Recent research has shown that during the course of a campaign, investors are influenced by this information. In particular, stating that the CEO holds a university degree, reputable investor backing, large investments of other investors, and updates increase the willingness to invest, while offering high equity stakes reduces it (see Section "Hypotheses development").

Regarding venture success after the crowdfunding campaign, we find that ventures that state that their CEO holds a university degree are less likely to fail. A higher number of business-related updates is associated with a lower risk of failure. The number of updates on external certification, promotions, and the team is associated with a higher risk of failure. Contradicting the expectation, we find that high equity stakes offered increase the probability of survival, while large investments during the campaign result in higher failure probabilities. These results suggest that investors are partly using wrong signals and challenge the wisdom of the crowd. Furthermore, we find that ventures with

${ }^{10}$ However, when more data is available, performing robustness checks using (non-aggregated) data from other platforms would be worthwhile. 
the legal form "entrepreneurial company" or ventures that ran several crowdfunding campaigns bear a higher risk of failure, while older and larger ventures and ventures with CEOs who have work experience in the industry of the startup are less likely to fail.

These results have implications for investors, entrepreneurs, and platform design as they provide guidance on the signals that are worth sending or using. Credible signals that entrepreneurs can send include indicating their university degree and avoiding choosing a legal form with low liability. Investors should not use the number of updates on campaign development, external certification, promotions, and the team; large investments of others; and offering a low equity stake as quality signals, if their goal is to minimize the risk of failure. Our finding that large investments are related to a higher risk of failure emphasizes the importance of regulating large investments in equity crowdfunding. Platforms could help reduce the misinterpretation of large investments by providing information on investors' level of professionalism or investment experience. Furthermore, the maximum amount that may be invested could be made dependent on investors' professionalism or investment experience. Moreover, investors in later financing rounds, such as venture capitalists, can better assess failure risks by using our results on signals generated during the crowdfunding campaign.

\begin{abstract}
Abbreviations
AG: "Aktiengesellschaft" (public limited company); AIC: Akaike information criterion; AME: Average marginal effect; BA: Business angel; CEO: Chief executive officer; GmbH: "Gesellschaft mit beschränkter Haftung " (limited liability company); SD: Standard deviation; UG: "Unternehmergesellschaft" (entrepreneurial company); UK: United Kingdom; US: United States; VC: Venture capitalist.
\end{abstract}

\title{
Acknowledgements
}

We thank the editor for handling our manuscript, the anonymous reviewers for their valuable comments and suggestions and the staff of the chair of Finance and Investment at the Technische Universität Berlin for their help with data collection.

\section{Authors' contributions}

FR made the largest contribution to data collection. Both authors made significant contributions regarding the literature research, conception, methods and interpretation of results. The implementation in $\mathrm{R}$, under regular consultation with FR, was done by MW. MW was a major contributor in writing the manuscript. Both authors read and approved the final manuscript.

\section{Funding}

The authors received no specific funding for this work.

\section{Availability of data and materials}

The datasets generated and analyzed during the current study are available from the corresponding author on reasonable request.

\section{Declarations}

Competing interests

The authors declare that they have no competing interests.

Received: 26 May 2020 Accepted: 25 June 2021

Published online: 05 July 2021

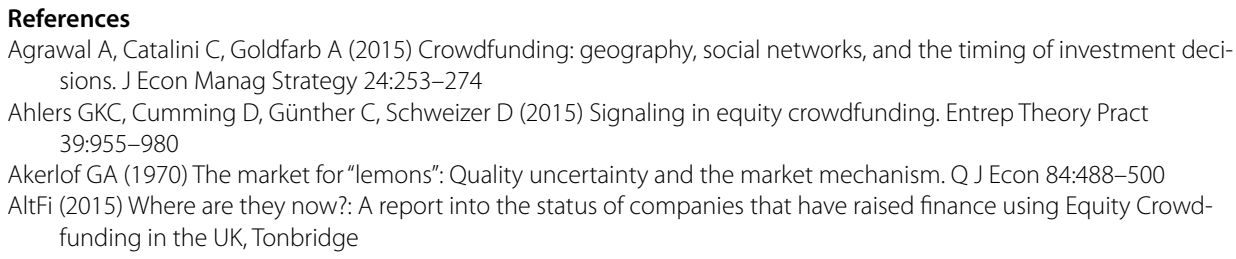


Amihud Y (2002) Illiquidity and stock returns: cross-section and time-series effects. J Financial Mark 5:31-56

Angerer M, Brem A, Kraus S, Peter A (2017) Start-up funding via equity crowdfunding in Germany: a qualitative analysis of success factors. J Entrep Finance 19:1-34

Arrow KJ (1984) The economics of agency, Technical Report Nr. 451, Stanford

Bade M, Walther M (2021) Local preferences and the allocation of attention in equity-based crowdfunding. Rev Manag Sci. https://doi.org/10.1007/s11846-020-00429-6

Belleflamme P, Lambert T, Schwienbacher A (2014) Crowdfunding: tapping the right crowd. J Bus Ventur 29:585-609

Block J, Hornuf L, Moritz A (2018a) Which updates during an equity crowdfunding campaign increase crowd participation? Small Bus Econ 50:3-27

Block JH, Colombo MG, Cumming DJ, Vismara S (2018b) New players in entrepreneurial finance and why they are there. Small Bus Econ 50:239-250

Block JH, Groh A, Hornuf L, Vanacker T, Vismara S (2020) The entrepreneurial finance markets of the future: a comparison of crowdfunding and initial coin offerings. Small Bus Econ. https://doi.org/10.1007/s11187-020-00330-2

BMJV (2020a) Bundesanzeiger. https://www.bundesanzeiger.de. Accessed 22 May 2020

BMJV (2020b) Unternehmensregister. https://www.unternehmensregister.de. Accessed 22 May 2020

Capizzi V, Carluccio EM (2016) Competitive frontiers in equity crowdfunding: the role of venture capitalists and business angels in the early-stage financing industry. In: Bottiglia R, Pichler F (eds) Crowdfunding for SMEs: a European perspective. Springer, London, pp 117-157

Cholakova M, Clarysse B (2015) Does the possibility to make equity investments in crowdfunding projects crowd out reward-based investments? Entrep Theory Pract 39:145-172

Companisto (2020). https://www.companisto.com/de. Accessed 22 May 2020

Cox DR (1972) Regression models and life-tables. J R Stat Soc 34:187-202

Crowdfunding.de (2018) Crowdinvest Marktreport 2018 Deutschland: Markterhebung durch crowdfunding.de. https:// www.crowdfunding.de/wp-content/uploads/2019/03/Crowdinvest-Marktreport-2018-Deutschland-crowdfunding. de_pdf. Accessed 25 August 2019

Crowdinvest (2020) Crowdinvest.de: Datenbank und Erfolgsmonitor für Crowdinvestments. https://www.crowdinvest. de/. Accessed 1 November 2020

Cumming D, Meoli M, Vismara S (2019) Investors' choices between cash and voting rights: evidence from dual-class equity crowdfunding. Res Policy 48:103740

Cumming D, Meoli M, Vismara S (2021) Does equity crowdfunding democratize entrepreneurial finance? Small Bus Econ 56:533-552

North Data (2020). https://www.northdata.de. Accessed 22 May 2020

Dorfleitner G, Hornuf L, Weber M (2018) Dynamics of investor communication in equity crowdfunding. Electron Mark 28:523-540

Goethner M, Luettig S, Regner T (2020) Crowdinvesting in entrepreneurial projects: disentangling patterns of investor behavior. Small Bus Econ. https://doi.org/10.1007/s11187-020-00332-0

Grambsch PM, Therneau TM (1994) Proportional hazards tests and diagnostics based on weighted residuals. Biometrika 81:515-526

Hall R, Woodward S (2010) The burden of the nondiversifiable risk of entrepreneurship. Am Econ Rev 100:1163-1194

Harrell F, Lee K, Mark D (1996) Multivariable prognostic models: issues in developing models, evaluating assumptions and adequacy, and measuring and reducing errors. Stat Med 15:361-387

Hasan M, Le T, Hoque A (2021) How does financial literacy impact on inclusive finance? Financial Innov 7:40

Heminway JM (2013) Investor and market protection in the crowdfunding era: disclosing to and for the crowd. Vt Law Rev 38:827-848

Hornuf L, Schmitt M (2016) Success and failure in equity crowdfunding. Cesifo DICE Report 14:16-22

Hornuf L, Schwienbacher A (2017) Should securities regulation promote equity crowdfunding? Small Bus Econ 49:579-593

Hornuf L, Schwienbacher A (2018) Market mechanisms and funding dynamics in equity crowdfunding. J Corp Finance 50:556-574

Hornuf L, Schmitt M, Stenzhorn E (2018) Equity crowdfunding in Germany and the United Kingdom: follow-up funding and firm failure. Corp Gov 26:331-354

Hornuf L, Schmitt M, Stenzhorn E (2020) Does a local bias exist in equity crowdfunding? Max Planck Institute for Innovation \& Competition Research Paper (16-07)

Hougaard P (2000) Analysis of multivariate survival data. Statistics for Biology and Health, New York

Kalbfleisch JD, Prentice RL (1980) The statistical analysis of failure time data. Wiley, New York

Lambert T, Ralcheva A, Roosenboom P (2018) The crowd-entrepreneur relationship in start-up financing. In: Cumming D, Hornuf $L$ (eds) The economics of crowdfunding: startups, portals and investor behavior. Springer, Cham, pp 57-78

Leboeuf G, Schwienbacher A (2018) Crowdfunding as a new financing tool. In: Cumming D, Hornuf L (eds) The economics of crowdfunding: startups, portals and investor behavior. Palgrave Macmillan, US, Cham, pp 11-28

Leland HE, Pyle DH (1977) Informational asymmetries, financial structure, and financial intermediation. J Finance 32:371-387

Markowitz H (1952) Portfolio selection. J Finance 7:77-91

McFadden D (1987) Regression-based specification tests for the multinomial logit model. J Econom 34:63-82

Mollick E, Nanda R (2015) Wisdom or madness? Comparing crowds with expert evaluation in funding the arts. Manag Sci 62:1533-1553

Ng AW, Macbeth D, Yip LSC (2017) Exploring performance drivers for technology-based ventures from early stage to expansion: Perspectives of venture capitalists. Ventur Cap 19:335-359

Pichler F, Tezza I (2016) Crowdfunding as a new phenomenon: Origins, features and literature review. In: Bottiglia R, Pichler F (eds) Crowdfunding for SMEs: a European perspective. Palgrave Macmillan UK, London, pp 5-43

Piva E, Rossi-Lamastra C (2018) Human capital signals and entrepreneurs'success in equity crowdfunding. Small Bus Econ 51:667-686 
Puri M, Zarutskie R (2012) On the life cycle dynamics of venture-capital- and non-venture-capital-financed firms. J Finance 67:2247-2293

Rossi A, Vismara S (2018) What do crowdfunding platforms do? A comparison between investment-based platforms in Europe. Eurasian Bus Rev 8:93-118

Rossi A, Vismara S, Meoli M (2019) Voting rights delivery in investment-based crowdfunding: a cross-platform analysis. J Ind Bus Econ 46:251-281

Securities and Exchange Commission (2015) SEC adopts rules to permit crowdfunding: proposes amendments to existing rules to facilitate intrastate and regional securities offerings. https://www.sec.gov/news/pressrelease/2015-249. html. Accessed 18 May 2020

Seedmatch (2018) Fundingindex 2018. https://seedmatch-10ddc.kxcdn.com/fuer-investoren/Fundingindex. pdf. Accessed 14 May 2020

Signori A, Vismara S (2016) Returns on investments in equity crowdfunding, SSRN 2765488

Signori A, Vismara S (2018) Does success bring success? The post-offering lives of equity-crowdfunded firms. J Corp Finance 50:575-591

Spence M (1973) Job market signaling. Q J Econ 87:355-374

Spence M (2002) Signaling in retrospect and the informational structure of markets. Am Econ Rev 92:434-459

Stiglitz JE (1975) The theory of "screening", education, and the distribution of income. Am Econ Rev 65:283-300

Stubner S, Wulf T, Hungenberg $\mathrm{H}$ (2007) Management support and the performance of entrepreneurial start-ups. Schmalenbach Bus Rev 59:138-159

Surowiecki J (2004) The wisdom of crowds: why the many are smarter than the few and how collective wisdom shapes business, economies, societies, and nations. Doubleday, New York

Tech R (2018) Financing high-tech startups: Using productive signaling to efficiently overcome the liability of complexity. Springer International Publishing, Cham

Therneau T, Atkinson E (2020) Concordance. https://cran.r-project.org/web/packages/survival/vignettes/concordance. pdf. Accessed 11 November 2020

Tjur T (2009) Coefficients of determination in logistic regression models-a new proposal: The coefficient of discrimination. Am Stat 63:366-372

Vismara S (2016) Equity retention and social network theory in equity crowdfunding. Small Bus Econ 46:579-590

Vismara S (2018a) Information cascades among investors in equity crowdfunding. Entrep Theory Pract 42:467-497

Vismara S (2018b) Signaling to overcome inefficiencies in crowdfunding markets. In: Cumming D, Hornuf L (eds) The economics of crowdfunding: startups, portals and investor behavior. Palgrave Macmillan US, Cham, pp 29-56

Vittinghoff E, McCulloch CE (2007) Relaxing the rule of ten events per variable in logistic and Cox regression. Am J Epidemiol 165:710-718

Walther M, Bade M (2020) Observational learning and willingness to pay in equity crowdfunding. Bus Res 13:639-661

Wang H, Kou G, Peng Y (2021) Multi-class misclassification cost matrix for credit ratings in peer-to-peer lending. J Oper Res Soc 72:923-934

Wholey DR, Brittain JW (1986) Organizational ecology: findings and implications. Acad Manag Rev 11:513-533

\section{Publisher's Note}

Springer Nature remains neutral with regard to jurisdictional claims in published maps and institutional affiliations.

\section{Submit your manuscript to a SpringerOpen ${ }^{\circ}$ journal and benefit from:}

- Convenient online submission

- Rigorous peer review

- Open access: articles freely available online

- High visibility within the field

- Retaining the copyright to your article

Submit your next manuscript at $\boldsymbol{\nabla}$ springeropen.com 